\title{
Psychodiagnostic toolkit of combat stress for aviation specialists
}

\author{
Sergey Maksymenko ${ }^{1}$, Oleg Blinov ${ }^{2, *}$, Yuliya Shatilo², and Ivan Timkin ${ }^{2}$ \\ ${ }^{1}$ G. S. Kostiuk Institute of Psychology of the National Academy of Educational Sciences of Ukraine, \\ 2 Pankivska ave., Kyiv, 01033, Ukraine \\ ${ }^{2}$ National Aviation University, 1 Liubomyra Huzara ave., Kyiv, 03058, Ukraine
}

\begin{abstract}
The article is dedicated to the analysis of psychological techniques used in psychological practice to determine the combat stress among aviation professionals. The relevance of the article is due to the active interest of modern researchers in this problem as the appropriate psychological toolkit doesn't exist. The study is performed in compliance with medical psychology, together with the study of combat stress phenomenology and the development of psychological tools for psychodiagnostics, psychocorrection, and psychotherapy. The author presents express-methods that allow both to establish the signs of combat stress and to assess it in points, to work with tools in the field at any weather and season or hospital conditions. The suggested comprehensive approach to the study of the combat stress phenomenon among the specialists through its understanding of the integrative internal content where one of its elements is psychological resources. This approach allows us to study combat stress in the dynamics of its changes, as a state of mental stress among the servicemen during their adaptation to combat conditions using the resource potential. The analysis showed that the proposed methods are universal and allow a comprehensive consideration of the combat stress problem among the servicemen.
\end{abstract}

\section{Introduction}

The activities of the aviation specialists take place in extreme conditions, and the leading ones are psychological: a constant element of risk and danger to life; the need to act in specific conditions of professional tasks; the lack of information during the stay on the aircraft; limited time to perform the necessary actions; the necessity to be ready to perform a parachute jump, etc. The action of stress factors mainly negatively affects the professionals and encourages chronic fatigue, anxiety, fear, panic attacks, mental disorders, errors in professional activities and under certain conditions, a reduced performance, complete disorganization or failure [1-7].

The main element of pilots' professional activity is a flight training, during which the perception of a threatening situation is subjective, and depends on the specifics of combat missions (emotional experience of stress-factors) or is carried out indirectly remotely

* Corresponding author: blinov09@bigmir.net 
(informational impact factor). In the process of adapting to the conditions of combat operations, the servicemen are in a state of mental stress, in which their experiences and comprehension of what they saw, heard, and felt take place. This requires significant consumption of psychological resources from combatants. They have both short-term adaptive responses aimed at adapting to unusual factors of the combat conditions, and the long-term ones, that allow the servicemen to survive in extreme conditions. The servicemen's experience of combat stress encourages a change in priorities in the adaptation of servicemen to professional activities, the choice of the most optimal coping strategies for them [8-16].

The studies have shown that several reasons do not allow a full-scale study of combat stress on a scientific basis. The reason is the lack of appropriate tools. The researchers use indicators of various tests and questionnaires to establish the changes in the psyche of servicemen as a result of combat stress. An urgent issue today is the development and testing of the psychological toolkit of combat stress [17-20].

Today's conditions require the organization and realization of a large-scale psychological work with specialists, the organization of a system of their psychological protection against combat stress. All the above led to the choice of the purpose of the article - to determine the psychodiagnostic toolkit of combat stress for aviation specialists.

\section{Research methods and techniques}

The choice of methods and techniques for the study of combat stress is due to the existing problem of its assessment and the provision of effective psychological assistance to the military service victims from its traumatic impact. The organization of work was performed based on the definition of combat stress as a state of mental stress of servicemen in the process of their adaptation to the conditions of combat activities using the resource potential [17].

As a result of the analysis of literature sources and expert assessment, was established the absence of a psychological toolkit to assess combat stress and in the field allows a psychocorrection of the consequences of its impact. We have developed psychological techniques, which, after appropriate procedures of mathematical and statistical data processing, made it possible to research on combat stress, both among the military personnel and the wounded, contused, and those who underwent treatment in a hospital setting.

The developed psychological toolkit for rapid assessment of combat stress and its regulation showed fairly high efficiency and provided an opportunity to solve the problem of comprehensive control and monitoring of combat stress while using a Combat stress questionnaire by Blinov O. A. (CSQB); Screening questionnaire for posttraumatic stress disorder (SQ PTSD) (O. Blinov, S. Maksymenko, I. Chernenko); express scale for determining well-being, mood and activity (WMA); a tablet for work with an eight-color test by M Luscher; a deck of metaphorical associative photographs "Stress-stop!"; a deck of metaphorical associative cards "Compass of choosing a profession". Psychological tools are designed to work in the field, natural, and hospital conditions [17-20].

With the help of the above author's psychological tools, the very new data on the particular properties of the combat stress manifestation among aviation specialists were obtained. 


\section{Results and discussions}

The work on the development of the psychological toolkit, its verification, and testing was organized in three stages.

At the first stage, we have developed methods for the implementation of psychodiagnostics of combat stress. These include a Combat stress questionnaire by Blinov O. A. (CSQB); a Screening questionnaire for post-traumatic stress disorder (SQ PTSD) (O. Blinov, S. Maksymenko, I Chernenko).

1. The Combat stress questionnaire by Blinov O. A. (CSQB) is designed to determine the level of psychological stress among the professionals who have participated in lifethreatening activities; to establish the degree of their adaptability to action under extreme conditions; the availability of human resources to overcome the effects of traumatic stress [17].

The methodological basis of the questionnaire is H. Selye's concept of stress; R. Lazarus's understanding of stress psychology, R. Abdurakhmanov's, L. Kitaev-Smyk's, O. Karayani's ideas about combat stress; S. Freud's concept of "military neurosis", M. Horowitz's post-traumatic stress disorders; ideas about the phenomenon of combat mental trauma by M. Reshetnikov, S. Litvintsev, E. Snedkov, O. Reznik, O. Syropyatov; S. Maksymenko's concept of need, existence, and self-development of personality; multidimensional model of psychological survival of a person after severe stress BASIC Ph by M. Laad, etc.

The questionnaire consists of 24 questions, which are divided into four subscales, namely: the subscales for the definition of acute and post-traumatic stress disorder, the subscales of resource issues, the subscales of externally and internally mediated stressors that emotionally affect the individual. The content of the PTSD criteria according to DSM$\mathrm{V}(2013)$ is revealed in the questions.

The answers to the questionnaire are evaluated on a 5-point scale by R. Likert and reveal the features of personal opinion about combat stress. Analysis of personal changes under stress is carried out at the cognitive, affective, motivational, and behavioural levels of the mental sphere of a person.

Based on the results of the answers, an integrated indicator is compiled, which is calculated as the arithmetic mean of the total sum of all digital choices of the respondent (the value of the results of the four subscales). Its level is determined on the scale of combat stress. Depending on the value of the integrated indicator, the stage of stress development among the serviceman is established and a description of the adaptive characteristics is offered.

The questionnaire has a graphical component that provides visualization of a personal psychological portrait of the individual as a result of combat stress and has a form of a three-level circle, a so-called "clock".

2. We have developed, verified, and tested a Screening questionnaire for posttraumatic stress disorder (SQ PTSD). It is developed based on the modern regulatory framework and it allows to quickly establish the signs of post-traumatic stress disorders among the specialists [18].

The advantages of the questionnaire are: the content of the questions meets the criteria of DSM-V; adaptability to the domestic linguistic socio-cultural environment; verification procedure is performed; satisfies the existing need for psychological express tools for working with a significant number of people; it is simple and convenient to use as psychological toolkit under the conditions limited by time, in the field, etc .; allows to carry out psychodiagnostics both with civilians and with servicemen.

The questionnaire consists of: 
1) The annotation, which records biographical information, the period of participation in extreme conditions, the presence of injuries, etc.

2) The tables of three columns. In the first one the numbering is given, there are 7 questions in the second, and in the third - the options to the answers to each question "yes" or "no" are offered.

3) After providing answers to the questions, the respondent is asked to establish the level of complexity of the existing problem of the respondent.

When working with the questionnaire, the respondent must answer "yes" if he agrees with the question asked, or "no" if he does not agree. Next, the number of questions to which positive answers were given is counted.

It is considered that 2 positive responses indicate the presence of sub-threshold signs of PTSD (adaptation disorders); 3 positive answers show the incomplete clinical manifestations of PTSD, so there is a need for in-depth examination; 4 or more positive responses indicate the likelihood of PTSD.

The time for the survey procedure and the processing of results is up to 2 minutes.

We conducted a study of combat stress among the servicemen, where 690 people took part with the help of the Combat stress questionnaire by Blinov O. A. (CSQB) and the Screening questionnaire for post-traumatic stress disorder (SQ PTSD). 408 soldiers (59\%) took part in the combat activity.

To establish the psychological features of the combat stress manifestation among the servicemen - the participants in combat activities, a comprehensive assessment was conducted. The Mann-Whitney U test of rank similarities was applied. The main statistically significant differences are shown in table 1.

Table 1. Average rank indicators comprehensive assessment of servicemen who took part in combat activities and non-combatants.

\begin{tabular}{|c|c|c|c|c|c|}
\hline \multirow{2}{*}{ Indicators } & \multirow{2}{*}{ Value } & \multicolumn{2}{|c|}{$\begin{array}{c}\text { Participated in combat } \\
\text { operations }\end{array}$} & \multicolumn{2}{c|}{$\begin{array}{c}\text { Didn't participate in combat } \\
\text { operations }\end{array}$} \\
\cline { 3 - 6 } & & Rank & Average & Rank & Average \\
\hline SQ PTSD & 0.000 & 177.19 & 3.5 & 138.77 & 2.76 \\
\hline CSQB & 0.000 & 135.59 & 68.55 & 98.85 & 61.51 \\
\hline AS_PTSD & 0.000 & 136.93 & 21.14 & 95.20 & 17.69 \\
\hline RB & 0.057 & 128.03 & 16.84 & 110.08 & 15.72 \\
\hline sdfap & 0.137 & 126.54 & 14.96 & 112.69 & 14.36 \\
\hline sfiap & 0.001 & 133.14 & 15.88 & 101.14 & 13.85 \\
\hline
\end{tabular}

Where:

CSQB is an overall indicator of the combat stress questionnaire by Blinov O. A.

AS_PTSD is subscale № 1 CSQB. Acute stress and posttraumatic stress disorders.

$\mathrm{RB}$ is subscale № 2. Resource block.

sfdap is subscale № 3. Stress factors that directly affect the personality of the serviceman.

sfiap is subscale № 4. Stress factors that indirectly emotionally affect the personality of the serviceman.

SQ PTSD is a general indicator of the screening questionnaire for post-traumatic stress disorder (Blinov O. A., Maksymenko S. D., Chernenko I. O.).

Practical psychological work with the questionnaires proved their simplicity and high efficiency in use. The analysis of the results obtained showed that all the indicators of the 
CSQB and SQ PTSD questionnaires, the average values were higher among the servicemen who took part in military actions.

At the second stage of the formation of the psychological tool base, we developed a psychological toolkit for scoring the impact of combat stress in the form of an express scale for determining well-being, mood, and activity (WMA). A tablet was also developed to work with M. Luscher's eight-color test in the field.

3. The express scale for determining well-being, mood, and activity (WMA).

The express scale is a compact, informative express-tool for determining the functional status of patients in scores. It is developed based on the WMA test. In the express scale, it is offered to define a state of well-being, mood, and activity (WMA) on 10-point scales. In addition to the subjective definition of properties (categories), it is offered to make an integral indicator of them.

The sequence of work is offered to organize in the following order: read the instructions for working with the express scale, fold twice the form with the text, determine the appropriate numbers with levels of well-being, mood and activity, turn the sheet, and put it aside. After the psychocorrective work, the patient is asked to return to the form, circle the current points of properties (categories), unfold the sheet, and compare the results. The work with the express scale lasts no more than one minute. In practice, it has proven to be a highly effective psychological toolkit.

4. A device for working with the eight-color test of M. Luscher.

The present invention belongs to psychological tools and can be used as a mobile portable device which allows expanding the range of psychodiagnostic examination.

The device looks like a rectangular tablet measuring $250 \mathrm{~mm} \times 500 \mathrm{~mm}$. It is made of pressed cardboard. Its weight and density allows holding the tablet with one hand and provides the balance of the work surface.

The tablet has dimensions that provide horizontal placement in one row of eight colored cards of the M. Luscher test.

Horizontally from one edge of the tablet in parallel to each other, there are two "pockets" for placing color cards in them. To make the "pockets", dense transparent plastic is used, which provides a stable fixed position of the cards. The height of the wall of a "pocket" is $40 \mathrm{~mm}$. The first pocket is located on the bottom edge of the tablet. The second "pocket" is located on its upper edge. Between the pockets, there is a free space of $170 \mathrm{~mm}$ x $500 \mathrm{~mm}$.

The "pockets" are horizontal and thus provide a consistent perception of the colorful series of cards and the implementation of their movement in the plain of the device.

To carry it, it is folded once vertically in the centre of the device. As a result of folding it gets to the sizes of $250 \mathrm{~mm} \times 250 \mathrm{~mm}$.

To bring the device into working condition, it is necessary to unfold it and place it in a horizontal plane in front of a specialist.

The device for working with the eight-color test of M. Luscher has received a patent for a utility model.

At the third stage, the decks of metaphorical associative photocards "Stress-stop!", as well as the decks of metaphorical associative cards "Compass of choosing a profession" were developed. They allow providing adequate psychological assistance to aviation specialists who are in a state of combat stress.

5. A deck of metaphorical associative photo-cards "Stress-stop!".

It belongs to the method of psychological surgery and as a psycho-correctional tool allows organizing quickly both the prevention of stress and various forms of work with its manifestations.

The deck of metaphorical associative photo-cards is designed to work with adverse emotional states of a person. 
The set consists of:

- 108 pieces of original metaphorical associative photos, where you will find 36 pieces of cards with dark "shirts" depicting various subjects that cause adverse emotions, as well as 72 resource cards that allow changing the vector of emotions in a positive way to solve existing problems;

- 3 work cards for in-depth stress analysis;

- 30 word-cards with the names of emotions;

- instructions with examples of 21 exercises.

Used for individual and group work, family counselling, and coaching.

Can be used by psychologists, psychotherapists, social workers and for individual counseling, psychodiagnostics, and psychocorrection; for work with difficult life situations and post-traumatic stress disorders; in the process of psychological rehabilitation in combination with other psychological tools; when working on the prevention and treatment of psychosomatic diseases, etc.

The design of the deck (its packaging) is specially made to work in adverse weather (field) conditions.

For the deck of metaphorical associative photo-cards "Stress-stop!" was received a Certificate of registration of copyright to the work.

By the order of the Director of the Military Medical Department of the Ministry of Defence of Ukraine dated June 5, 2017, № 10, the deck of metaphorical associative photocards "Stress-stop!" is suggested for use in the practical work of doctors at hospitals, sanatoriums and outpatient clinics of the medical service of the Armed Forces of Ukraine; psychiatrists, psychotherapists, psychophysiologists, medical (clinical) psychologists, social psychologists, etc.

6. A deck of metaphorical cards "Compass of choosing a profession" will help to solve the problems with choosing a profession. As an express psychodiagnostic, psychocorrectional toolkit allows you to quickly establish the presence of professional preferences or their absence.

It can be used at schools to learn about types of professional activities; by psychologists, and social workers for professional orientation; for preparation and passing of professional psychological selection; in the process of psychological and medical-psychological rehabilitation, and for the selection of new professional activities, in employment centres, vocational guidance centres for children and adolescents, etc.

With the help of the cards the following tasks can be solved: to make a presentation in a simple accessible form of various professions; to accelerate the determination of a person's professional preferences through the emotional and figurative perception of their plots; to reveal the presence of sensitive professional personal qualities; to reveal human potentials; to make a psychological portrait of the person; to simulate situations of current and future activities; to reveal and model the manifestation of inner needs and preferences of a person in a certain type of work; to reveal human abilities to the group and teamwork.

The set consists of 108 pieces of metaphorical cards; instructions with examples of 15 exercises; 17 tips to quickly achieve a goal in life; a list of 70 business and personal qualities; 4 schemes-platforms for an in-depth study of psychological features of a personality and their correspondence to the chosen profession; profession selection matrix.

The plot of the cards is the author's image of people's daily lives, work clothes, and their professional activities. Metaphorical cards can be used from the age of 10. Used: for individual and group work, during coaching.

\section{Conclusions}

Aviation belongs to the professional activity of a person whose tasks are performed under 
extreme conditions. The leading ones are psychological. The action of stress factors mainly negatively affects the professionals and encourages chronic fatigue, anxiety, fear, panic attacks, mental disorders, errors in professional activities and under certain conditions, a reduced performance, complete disorganization, or failure.

The most common factor of a negative impact on professionals is combat stress. A comprehensive approach to the study of the phenomenon of combat stress among the specialists through its understanding as a state of mental stress of servicemen during their adaptation to the conditions of combat activities with the use of resource potential is proposed. It is the psychological resource potential of the soldiers' personality that acts as an internal regulator of the experience of combat stress.

For pilots, the main element of the professional activity is flight training. During its implementation, the perception of a threatening situation is subjective, and depends on the specifics of combat missions (emotional experience of the impact of the stress-factors) or is carried out indirectly remotely (the action of the informational impact factor). In the process of adapting to the conditions of combat activities, servicemen are in a state of mental stress, where they go through their experiences and comprehend what they saw, heard, and felt.

The impact of combat stress requires combatants to spend significant psychological resources. They have both short-term adaptive responses aimed at adapting to unusual factors of combat conditions, and long-term ones that allow servicemen to survive under extreme conditions. The experience of combat stress by servicemen encourages a change in priorities in the adaptation of servicemen to professional activities, to choose the most optimal coping strategies for them.

We developed a Combat stress questionnaire by Blinov O. A. (CSQB). It is designed to determine the level of psychological stress among the professionals who have participated in life-threatening activities; establish the degree of their adaptability to action under extreme conditions; availability of human resources to overcome the effects of traumatic stress. The questionnaire consists of 24 questions, which are divided into four subscales, namely: subscales for acute and post-traumatic stress disorder, subscales of resource questions, subscales of externally and internally mediated stressors that emotionally affect the individual.

The Screening questionnaire for post-traumatic stress disorder (SQ PTSD) (O. Blinov, S. Maksymenko, I. Chernenko) proved to be a highly effective tool. It is developed based on the modern regulatory framework and allows us to quickly establish the signs of posttraumatic stress disorders among specialists. The questionnaire consists of 7 questions to be answered - "yes" or "no". After answering the questions, the respondent is asked to establish the level of complexity of the existing problem.

The express scale of determining well-being, mood, and activity (WMA) is used in practice. This express scale is a compact, informative express tool for determining the functional status of patients in scores. It is offered to define the well-being, mood, and activity (WMA) on 10-point scales. In addition to the subjective determination of properties (categories), it is proposed to compile their integral indicator.

The developed tablet to work with the eight-color test of M. Luscher is an invention that belongs to the psychological toolkit and can be used as a mobile portable device that allows expanding the range of psychodiagnostic examination. Its weight and density allows to hold the tablet with one hand and provides a balance of the work surface. The tablet has dimensions that provide horizontal placement in one row of eight colored cards of the $\mathrm{M}$. Luscher test.

A deck of metaphorical associative photo cards "Stress-stop!" is used to work with adverse emotional states of aviation specialists. As a psycho-correctional toolkit, it allows to quickly organize both stress prevention and various forms of work with its 
manifestations. It consists of: 108 pieces of original metaphorical associative photographs; 3 work cards for in-depth stress analysis; 30 word-cards with names of emotions; instructions with examples of 21 exercises. It is used for individual and group work, family counseling, and coaching.

A deck of metaphorical cards "Compass of choosing a profession" will help to solve the problem of choosing a profession (especially for servicemen who lost limbs as a result of combat activities). As an express psychodiagnostic, and psychocorrectional toolkit it allows to quickly establish the presence of professional preferences or their absence. The deck of cards consists of 108 pieces of metaphorical cards; instructions with examples of 15 exercises; 17 tips to quickly achieve a goal in life; a list of 70 business and personal qualities; 4 schemes-platforms for in-depth study of psychological features of a personality and their correspondence to the chosen profession; profession selection matrix. Metaphorical cards can be used for individual, and group work, and during coaching.

The innovative psychological toolkit for combat stress of aviation specialists is developed to have a comprehensive approach to the psychodiagnostics of combat stress. Today's conditions require the organization and carrying out large-scale psychological work with specialists, the organization of a system for their psychological protection against combat stress.

\section{References}

1. D. Bergman, M. Gustafsson S. Berntson, E. Berntson, Military Psychology 31(6), 481489 (2019) https://doi.org/10.1080/08995605.2019.1670583

2. L. Reardon, W. Chappelle, T. Goodman, S. Cowper, L. Prince, W. Thompson, Psychological Trauma: Theory, Research, Practice, and Policy 8(1), 55-62 (2016) https://doi.org/10.1037/tra0000046

3. C. Bryan, T. Goodman, W. Chappelle, W. Thompson, L. Prince, Military Behavioral Health 6(1), 3-12 (2018) https://doi.org/10.1080/21635781.2017.1325803

4. A. G. Ferrier-Auerbacha, C. R Erbes, M. A Polusny, Journal of Psychiatric Research 44(7), 470-476 (2010) https://doi.org/10.1016/j.jpsychires.2009.10.010

5. L. Palmer, G. Thandi, S. Norton, et al., Journal of Psychiatric Research 109, 156-163 (2019) https://doi.org/10.1016/j.jpsychires.2018.11.023

6. M. B. Arenson, M. A. Whooley, T. C. Neylan, et al., Psychiatry Research 265, 224-230 (2018) https://doi.org/10.1016/j.psychres.2018.04.046

7. A. A Contractor, J. D. Elhai, T. H. Fine, M. B. Tamburrino, G. Cohen, E. Shirley, P. K. Chan, I. Liberzon, S. Galea, and J. R. Calabrese Journal of Psychiatric Research 68, 19-26 (2015) https://doi.org/10.1016/j.jpsychires.2015.05.014

8. C. J. Bryan, T. Goodman, W. Chappelle, L. Prince, and W. Thompson, Military Psychology 30(5), 437-448 (2018) https://doi.org/10.1080/08995605.2018.1478562

9. W. Chappelle, K. McDonald, L. Prince, et al., Military Psychology 26(5-6), 376-385 (2014)

https://www.tandfonline.com/doi/abs/10.1037/mil0000046?journalCode=hmlp20

10. L. Prince, W. L. Chappelle, K. D. McDonald, et al., Military Medicine 180(3), 171-178 (2015) https://doi.org/10.7205/MILMED-D-14-00397

11. J. D. Wood, C. M. Ware, T. Correll, et al., Military Medicine 183(9-10), 489-493 (2018) https://doi.org/10.1093/milmed/usx032

12. W. L. Chappelle, K. D McDonald, L. Prince, et al., Military Medicine 179(8), 63-70 (2014) https://doi.org/10.7205/MILMED-D-13-00501 
13. W. Chappelle, E. Skinner, T. Goodman, J. Swearingen, L. Prince, Military Behavioral Health 6(4), 357-367 (2018) https://doi.org/10.1080/21635781.2018.1436101

14. C. Bryan, T. Goodman, W. Chappelle, W. Thompson, L. Prince, Military Behavioral Health 6(1), 3-12 (2018) https://doi.org/10.1080/21635781.2017.1325803

15. H. A. Smith, J. A. Stephenson, C. E. Morrow, et al., Military Behavioral Health 3(1), 5-13 (2015) https://doi.org/10.1080/21635781.2014.995245

16. A. D. Ogle, J. A. Young, Military Psychology 28(3), 123-133 (2016) https://doi.org/10.1037/mil0000121

17. O. Blinov, Psychological Journal: Scientific Review 5(9), 32-43 (2017) https://doi.org/10.31108/1.2017.5.9.3

18. O. Blinov, Psychological Journal: Scientific Review 1(11), 26-37 (2018) https://doi.org/10.31108/1.2018.1.11.2

19. O. Blinov, Psychological Journal: Scientific Review 2(12), 9-22 https://doi.org/10.31108/2018vol12iss2

20. O. Blinov, Problems of modern psychology 38, 38-52 (2017) http://nbuv.gov.ua/UJRN/Pspl_2017_38_6 